\title{
RESTOS NÁUFRAGOS Y DERECHO INTERNACIONAL. LA CONVENCIÓN DE NAIROBI EN PERSPECTIVA*
}

\author{
David ENRÍQUEZ** \\ Patricia URIBE***
}

RESUMEN: El artículo busca hacer un acercamiento a la evolución normativa internacional de la remoción de los restos de naufragio, de cara al proceso de ratificación de la Convención de Nairobi de mayo de 2007. Asimismo, considera el régimen mexicano en la materia y las acciones que el gobierno federal ha tomado para solucionar el problema de embarcaciones varadas, hundidas y semihundidas en puertos mexicanos.

ABSTRACT: In the context of the ratification process of the Nairobi Convention of May 2007, the article aims to presenting an approach as to the evolution of the international legal regime on wreck removals. It further considers the Mexican regime on the subject, as well as the actions conducted by the federal government in order to solve the problem of grounded, sank and semi-sank vessels.

RÉSUMÉ: Cet article a le propos de faire un rapprochement a l'évolution normative international de le déménagement des restés de naufrage de face au procès de ratification de la Convention de Nairobi du mai, 2007. Egalement, considère le régime mexicain dans la matière et les actions que le gouvernement fédéral a pris pour solutionne le problème d'embarcations échoués, coulé et semi-coulé dans les ports mexicaines.

* Artículo recibido el 1 de agosto de 2008 y aceptado para su publicación el 30 de agosto de 2008 .

** Doctor en derecho; investigador titular en el Instituto Panamericano de Jurisprudencia e investigador nacional en el SNI; profesor del ITAM y de la UP.

*** Aspirante a licenciada en derecho por la UNAM y ayudante de investigación. 
SUMARIO: I. Introducción. II. El contexto: los armadores y sus prácticas en la historia de la navegación. III. Un primer derrotero en la búsqueda por la uniformidad internacional. El cuadrante se centra en el patrimonio cultural subacuático. IV. El complejo trazado de una ruta alternativa. Respuestas del derecho comparado y del derecho internacional más allá de la aproximación cultural. V. Recepción nacional. Regulación y políticas públicas en México. VI. La Convención de Nairobi. Un tratamiento integral a un problema contemporáneo. VII. Conclusiones.

\section{INTRODUCCIÓN}

La Convención de Nairobi, de mayo de 2007, sobre Remoción de Restos Náufragos representa el peldaño más importante en el camino de la uniformidad internacional en la materia. Como expondremos en estas notas, el ámbito espacial de validez de la Convención de Nairobi plantea todavía algunas dudas sobre el efectivo combate de los países ribereños ante la - vetusta y continua - práctica de armadores poco escrupulosos de abandonar sus embarcaciones en los recintos portuarios de terceros países, propiciando así accidentes marítimos. Sin embargo, es, por mucho, el mejor esfuerzo de la comunidad internacional por encontrar una solución integral a los problemas que plantean las diversas especies de derrelictos.

En este contexto, el objeto del presente artículo es tener un acercamiento a la evolución normativa de los restos de naufragio en la comunidad internacional, así como identificar los avances que algunas jurisdicciones han logrado sobre el tema. Con miras al proceso de ratificación y entrada en vigor de la Convención de Nairobi, se estudian, asimismo, algunos de los aspectos más relevantes del instrumento y se tiene en cuenta, tanto el régimen normativo nacional como lo que México - a través, principalmente, de la Secretaría de Comunicaciones y Transportes - 1leva a cabo, con el fin de solucionar el problema que embarcaciones varadas, hundidas y semihundidas de un sinfín de banderas representan en los puertos de nuestro país. 


\section{EL CONTEXTO: LOS ARMADORES Y SUS PRÁCTICAS EN LA HISTORIA DE LA NAVEGACIÓN}

La relación entre restos náufragos, remoción y derecho internacional es reciente. Ha sido en los últimos años que las organizaciones internacionales han incorporado en sus agendas el tema. Los trabajos de dichas organizaciones culminaron con la creación de instrumentos internacionales, los cuales representan un notable esfuerzo de la comunidad internacional mediante la armonización de criterios estatales a nivel internacional, la delimitación de derechos y obligaciones entre los países y el reconocimiento de la importancia en la implementación de mecanismos de cooperación.

Con anterioridad a la culminación de estos instrumentos, los individuos eran los artífices de normas de derecho consuetudinario relativas a la exploración y explotación comercial de dichos restos. Existían reglas bien consolidadas sobre los derechos derivados de aquel que conseguía la remoción, fundamentadas en el riesgo marítimo que entraña por sí misma la operación, su complejidad y costos; sin embargo, el elemento más importante para determinar la existencia de estos derechos correspondía al éxito de la actividad. Así podemos distinguir dos grandes rubros en las actividades llevadas a cabo por particulares: el rescate y el hallazgo. Las actividades de rescate tienen como propósito alejar del peligro a las embarcaciones —incluyendo su carga y tripulación-, sin otorgar derechos de propiedad al rescatista, es decir, la propiedad original es retenida por el dueño, aunque sí presupone una recompensa por la remoción. Las reglas de hallazgo, por otro lado, se predican en la noción del abandono del buque y de su carga, por lo cual, una exitosa actividad de encuentro le confiere a quien lo lleve a cabo derechos de propiedad sobre los bienes.

Estas reglas de costumbre se caracterizaban por la falta de requisitos técnicos, el criterio para determinar si un resto náufrago se encontraba en abandono se dejaba al arbitrio de aquel que lo descubría. De igual manera, dichas reglas no distinguían la naturaleza de los restos: su trascendencia histórica y cultural, así como el posible impacto al patrimonio cultural de la humanidad; no obstaculizaban un derecho de propiedad para su descubridor, por el contrario, el hallazgo representaba una gran riqueza dependiendo del momento histórico que reflejara. 
Como explica Ramón Corral, al estudiar el salvamento marítimo, éste hunde sus primeras raíces en el llamado naufragium del derecho romano. Así, como actividad organizada y lucrativa, encuentra sus orígenes en la labor encaminada a recuperar los bienes o restos de buques naufragados. Sin embargo, ello se llevó a cabo mediante arduos esfuerzos por reprimir y condenar los actos de despojo a los náufragos. ${ }^{1}$

Así pues, la legislación justinianea, al mismo tiempo que contempló la interdicción del despojo de los náufragos, se esforzó por ofrecer una protección a los bienes de las naves que surcaban las aguas del mar, o bien que yacían en la playa, después de ser empujadas por las olas. En efecto, el Digesto (libro XIV, título II) recoge la Ley Rodia sobre el alijo, dedicada a regular la echazón y normas de protección sobre los bienes vertidos al mar.

En contraste a la evolución encontrada en el derecho romano, en el ius naufragii del derecho feudal, las personas o cosas que procedían del naufragio en el mar o incuso en los ríos correspondían al señor de la ribera y sus habitantes. La Iglesia católica tuvo, sin duda, también un peso específico en el desarrollo de la figura. En efecto, los concilios de Roma (1078), Nantes (1112) o Letrán (1179) condenaron las acciones de insolidaridad y de depredación de naufragios. Esta tradición del derecho canónico permaneció por siglos, y explícitamente en una bula de Gregorio XIII de marzo de 1853 se desarrolló el respeto de los náufragos y se condenó el derecho de naufragio.

Desde luego, los ordenamientos atlánticos, incluidos las Reglas de Oléron, del siglo XII, o el Libro del Consulado del Mar, del siglo XIV, son ilustraciones de la regulación en materia de naufragio. Ya en la Edad Moderna, las Ordenanzas de la Marina de 1681 decididamente logran abolir el derecho de naufragio como principio general; encuadrándola en el sistema, como pena capital, sin posibilidad de perdón. ${ }^{2}$

1 Morral, Ramón, El salvamento marítimo, Barcelona, Bosch, 1997, p. 55.

2 Para analizar la evolución de la figura véase Ripert, Georges, Compendio de derecho marítimo, trad. de Pedro San Martín, Buenos Aires, Tipográfica Argentina, 1954, pp. 325 y ss.; Blas, Osvaldo, Compendio de derecho de la navegación, Buenos Aires, Depalma, 1993, pp. 553 y ss.; Lefebvre, Antonio et al., Manuale di diritto della navigazione, Milán, AG, pp. 761 y ss.; Vialard, Antoine, Droit maritime, París, PUF, pp. 53 y ss.; Baughen, Simon, Shipping Law, Londres, Cavendish, p. 319; Gilmore, Grant, The Law of Admiralty, Nueva York, Foundation Press, 1975, pp. 689 y ss.; Healy, Nicholas et al., Admiralty, Nueva York, West Publishing, pp. 763 y ss. 
Desde luego, la introducción de la figura en el derecho marítimo mexicano ocurre mediante las Ordenanzas del Consulado de Bilbao, de 1737, que, incluso, estuvieron vigentes durante los primeros años del México independiente. De ahí, habrían de trascender a los códigos de Comercio y, finalmente, a la legislación especializada en la materia marítima.

El fin de la Segunda Guerra Mundial cuestiona la validez de estas normas. ${ }^{3}$ El crecimiento acelerado de los restos náufragos, el saqueo de la carga, y el impacto ambiental de la remoción llevada a cabo por particulares son algunos de los factores determinantes para el establecimiento de reglas entre Estados. Ejemplos notables del impacto de descubrimientos marítimos para la comunidad internacional fueron el galeón español de Nuestra Señora de Atocha, el buque de guerra sueco VASA, así como los barcos de vapor R. M. S. Republic y el S. S. Central America.

Dichos descubrimientos atrajeron el interés de la comunidad científica y de los rescatistas marinos. Es así como por primera vez surgieron consideraciones políticas serias en torno al tratamiento de los restos náufragos, así como de su contenido. ${ }^{4} \mathrm{El}$ establecimiento de instrumentos universales, aceptando la incorporación de derechos y obligaciones de los Estados, en respuesta a lo que pudiese constituir una amenaza a la comunidad internacional representado por restos náufragos materiales, se convirtió en una tarea de primer orden.

Por lo anterior, podemos decir que el interés en la remoción de los restos náufragos en el derecho internacional se ha centrado en dos aspectos fundamentales: (i) el patrimonio cultural, representado por la riqueza histórica-cultural que en sí misma guardan algunos restos náufragos, y (ii) aquellos restos que escapan del ámbito del patrimonio cultural, pero que tienen un impacto frente a la comunidad internacional, ya sea que re-

3 Si bien el gran número de tratados concluidos al término de la Segunda Guerra Mundial no contemplan el patrimonio cultural subacuático, establecen un notable precedente sobre el esfuerzo de la comunidad internacional para la protección del patrimonio cultural. Entre ellos podemos citar: la Convención de La Haya de 1954 sobre la Protección de la Propiedad durante Conflicto Armado, la Convención de 1970 sobre los Mecanismos de Protección y Prevención en la Importación, Exportación o Transferencia Ilícita de la Propiedad Cultural, y la Convención de 1972 sobre la Protección del Patrimonio Mundial Cultural y Natural.

4 Regan, Rob, "When Lost Liners become Found: an Examination of the Effectiveness of Present Maritime Legal and Statutory Regimes from Protecting Historic Wrecks in International Waters with Proposals for Change", Tulane Maritime Law Journal, 29 Tul. Mar. L. 313, 2005. 
presenten un peligro para la navegación o por el impacto de la carga atrapada en los mismos..$^{5}$

\section{UN PRIMER DERROTERO EN LA BÚSQUEDA POR LA UNIFORMIDAD INTERNACIONAL. EL CUADRANTE SE CENTRA EN EL PATRIMONIO} CULTURAL SUBACUÁTICO

El concepto de patrimonio cultural subacuático fue utilizado por primera vez en un reporte del Consejo de Europa de 1978. La protección del patrimonio cultural subacuático presenta grandes desafíos para la comunidad internacional. La falta de consenso entre los países se centraba en cuestiones, como el momento en que un resto marítimo debía ser considerado pieza arqueológica, la temporalidad, el impacto de los restos en el desarrollo histórico de los pueblos y la actitud de los países frente a las actividades de rescate: ¿cómo debía ser trazada la línea divisoria entre pillaje y legítimas actividades científicas? ${ }^{6}$

\section{La Convemar}

El primer antecedente para la protección del patrimonio cultural marítimo en un tratado multilateral se encuentra en la Convemar. ${ }^{7} \mathrm{La}$ Convención establece obligaciones expresas de los Estados respecto a la remoción de restos con naturaleza histórica y arqueológica. ${ }^{8}$ El establecimiento de estos adjetivos fue objeto de debate durante los trabajos de la Convención, a pesar de ello se entiende que esta categorización deberá depender de la actitud de la comunidad internacional, así como de una civilización en particular, frente a los valores en la protección y cuidado de

5 Como se estudiará más adelante, el contenido de los hidrocarburos constituyen una pieza clave en la remoción de los restos náufragos.

6 Ripert, Georges, op. cit., nota 2, pp. 325 y ss.; Blas, Osvaldo, op. cit., nota 2, pp. 553 y ss.; Lefebvre, Antonio et al., op. cit., nota 2, pp. 761 y ss.; Vialard, Antoine, $o p$. cit., nota 2, pp. 53 y ss.; Baughen, Simon, op. cit., nota 2, p. 319; Gilmore, Grant, op. cit., nota 2, pp. 689 y ss.; Healy, Nicholas et al., op. cit., nota 2, pp. 763 y ss.

7 Antes de la terminología de la Convemar, el concepto de patrimonio cultural subacuático se establece por primera vez en un reporte del Consejo de Europa de 1978.

8 El término arqueológico fue insertado tras la participación de la delegación de Túnez, pues temía que los artefactos del Imperio bizantino pudieran escapar de una definición acotada que incluyera únicamente el término histórico. 
los restos específicos, aunado al establecimiento de autoridades nacionales e internacionales para su preservación. ${ }^{9}$

Los artículos de la Convemar relacionados específicamente con la remoción y el patrimonio cultural son el 149 y el 303. El primero señala que sobre los objetos de naturaleza arqueológica e histórica sumergidos en alta mar se deberán otorgar derechos preferenciales para el Estado del cual sean originarios. El segundo artículo establece la obligación de todo Estado ribereño de proteger objetos de naturaleza arqueológica e histórica encontrados en el mar, así como la obligación de cooperar con otros Estados para llevar a cabo este fin.

Por lo anterior, podemos señalar que de acuerdo con una interpretación armónica con el resto de las disposiciones de la Convención, la Convemar establece una serie de regímenes legales con distinto ámbito de aplicación dependiendo del lugar en el cual se encuentren los restos: primero, los Estados ribereños tienen la obligación de proteger dichos restos cuando se encuentren bajo su jurisdicción absoluta, es decir, en sus aguas interiores, aguas territoriales y archipelágicas. Segundo, en la zona contigua los Estados tienen el derecho de controlar la remoción de objetos de naturaleza histórica y arqueológica dentro del lecho marítimo y hasta un límite de 24 millas náuticas desde la línea costera. Tercero, en la plataforma continental, la zona económica exclusiva y alta mar, el concepto de libertad del mar persiste, ningún Estado tiene jurisdicción o derechos soberanos sobre los restos marítimos, pero mantiene la obligación de proteger los objetos con naturaleza histórica o arqueológica. En atención al cumplimiento de estas obligaciones, los Estados han emitido legislación solicitando a las compañías de exploración petrolera y mineral comuniquen cualquier hallazgo de objetos que pudieran identificar durante dicha exploración. ${ }^{10}$

Cuarto, el último régimen legal se establece en el lecho marino, el suelo marino y el subsuelo, más allá de la jurisdicción nacional, esta franja es conocida como "el área" de conformidad con el artículo 149. Dentro de esta zona, los Estados tienen la obligación de preservar y disponer de los objetos de naturaleza histórica-arqueológica para el benefi-

9 Allain Jean, "Maritime Wrecks: where the Lex Ferenda of Underwater Cultural Heritage Collides with the Lex Lata of the Law of the Sea Convention", Viriginia Journal of International Law, 38 Va. J. Int'1 L. 747, 1998.

10 Idem. 
cio de la humanidad en su totalidad, particularmente en beneficio de los Estados que pueden reclamar dichos objetos.

La denominada área es de especial interés para la protección del patrimonio cultural de la humanidad. En virtud del artículo 149, las obligaciones de los Estados pueden ser consideradas como un obstáculo a las reglas generales de protección, ya que no establece quién deberá preservar o disponer de dichos objetos. Sin ninguna entidad internacional designada para esta tarea, queda en los Estados asumir las obligaciones específicas a nombre de la humanidad en su conjunto.

Sin embargo, la manera en la que están descritas las obligaciones de los Estados en el artículo 149 plantea las siguientes cuestiones: ¿qué deberá entenderse por país de origen?, ¿cómo se van a determinar los derechos preferenciales de los Estados? Basta recordar lo expuesto por la Corte Internacional de Justicia en la sentencia del caso de las Pesquerías en donde afirmó que la preferencia implica cierta prioridad, pero no puede involucrar la extinción de derechos concurrentes de otros Estados, es así como la determinación de los derechos deberá ser a través de negociación que defina y delimite su extensión. ${ }^{11}$ Este análisis no resuelve de manera definitiva la concurrencia de los derechos preferenciales, bastará, entonces, agotar los mecanismos diplomáticos y hacer un análisis en cada caso con la participación de expertos.

No obstante el importante avance que presenta la Convención, ésta no otorgó respuestas específicas a las grandes encrucijadas técnicas y procedimentales que entraña el patrimonio cultural subacuático. De igual manera, el patrimonio cultural era una cuestión que debía corresponder a la comunidad internacional en su totalidad, por el contrario, las disposiciones de la Convemar quedarían reservadas únicamente a los países parte. $^{12}$

\section{Documentos posteriores a la Convemar}

Una vez concluida la Convemar, los países iniciaron un importante proceso legislativo. Fue a nivel regional o mediante la intervención en

11 Fisheries Jurisdiction Case (United Kingdom vs. Iceland), Fondo del Asunto [1973] CIJ Rep 3.

12 Vialard, Antoine, op. cit., nota 2, pp. 53 y ss.; Baughen, Simon, op. cit., nota 2, p. 319; Gilmore, Grant, op. cit., nota 2, pp. 689 y ss.; Healy, Nicholas et al., op. cit., nota 2, pp. 763 y ss. 
organizaciones internacionales que se adoptaron instrumentos específicamente relacionados con el patrimonio cultural subacuático. En 1985 se elaboró un proyecto de convención sobre la protección del patrimonio cultural subacuático, aun cuando nunca fue adoptada, el Consejo de Europa retomó la preocupación por la protección del patrimonio cultural subacuático, partiendo de una revisión minuciosa de la Convención Europea para la Protección del Patrimonio Arqueológico, la cual fue adoptada en 1969, y cuyo objetivo era la protección de las antigüedades de tierra con una limitada aplicación al patrimonio sumergido. La revisión de 1992 le otorgó un mayor ámbito de aplicación al incluir el patrimonio cultural subacuático, el cual fue clasificado como los objetos remanentes y trazos de humanidad de épocas pasadas siempre y cuando estuviesen localizados en un área dentro de la jurisdicción de las partes.

En 1989, la Organización Marítima Internacional elaboró una convención para regular las actividades de rescate. Aun cuando el espectro del patrimonio cultural subacuático fue limitado, de acuerdo con el artículo 30, los Estados podían hacer reservas cuando los restos náufragos tuvieran características culturales prehistóricas, arqueológicas, y estuvieran situados en el lecho marítimo.

\section{La Convención de Buenos Aires de 1994}

La Convención de Buenos Aires de 1994 es el segundo antecedente importante para el patrimonio cultural subacuático. Este instrumento fue realizado por la Asociación de Derecho Internacional —organización privada con sede en Londres-, la cual en 1988 elaboró una serie de reportes sobre la importancia del patrimonio cultural. El trabajo de esta Asociación fue reconocido en 1994 con la adopción de la Convención de Buenos Aires para la Protección del Patrimonio Cultural Subacuático.

Aun cuando esta Convención nunca fue ratificada, representa un gran avance en la materia, ya que establece requisitos específicos - como el de la temporalidad - para determinar si un bien es declarado en estado de abandono. La caracterización de un objeto como poseedor de una naturaleza histórica y cultural se refleja en la Convención, lo cual se define como un resto de herencia cultural que se ha encontrado perdido o abandonado, o ha estado sumergido, por 100 años. En los comentarios de la Convención, el Comité de la ADI reconoce que no existen bases científicas para el establecimiento de la regla de 100 años, y señala que el 
mejor razonamiento para esta regla es de conveniencia administrativa, debido a que esta temporalidad se encuentra en la mayoría de los ordenamientos legales internos y en la práctica de los Estados. La gran mayoría de los países con legislación doméstica regulando restos históricos marítimos o terrestres han utilizado este margen, el cual refleja la existencia de una norma de derecho consuetudinario internacional. ${ }^{13}$

De igual manera establece una novedosa jurisdicción de conformidad con el artículo 1o. (3), el cual determina como zona de patrimonio cultural el área que se encuentra más allá del mar territorial fuera de los límites de la plataforma continental de conformidad con las reglas aplicables y los principios de derecho internacional.

A este respecto, el presidente del Comité de la ADI sobre Patrimonio Cultural, así como el relator especial señalaron que el establecimiento de esa nueva jurisdicción internacional estaba justificada: 1) por la existencia de una infectiva e insuficiente protección otorgada a los objetos de naturaleza arqueológica e histórica de acuerdo con lo establecido en el artículo 303 de la Convemar, 2) por el gran número de legislación interna que otorgaba a los Estados la posibilidad de actuación más allá de la zona contigua, y 3) por contradicción entre la jurisdicción señalada por la Convención Europea de 1992 y otros instrumentos — entre ellos la Convemar- Las mayores críticas a la Convención se fundamentaron en la existencia de este artículo.

Tal y como lo señaló Tommy Boh, presidente de la tercera conferencia de la Convemar: las provisiones de la Convención forman un paquete completo que se encuentra interrelacionado, los derechos y las obligaciones van de la mano, por lo cual, no es posible reclamar derechos bajo la Convención sin tener la obligación correspondiente. ${ }^{14}$

Además, este paquete completo necesita que cada provisión en lo individual del texto sea balanceado con todo su contexto. Contrario a estos principios, la Convención de Buenos Aires mediante el establecimiento de una zona de patrimonio cultural, no brinda derechos igualitarios a todo los Estados. Por el contrario, desconoce el consenso llevado a cabo en el marco de la Convemar entre los Estados ribereños y los Estados que se encuentran geográficamente sin acceso a los mares. De igual manera, los Estados ribereños que no han declarado la existencia de una 
zona de patrimonio cultural subacuático tendrían también libertad restringida en alta mar.

La Convención de Buenos Aires de 1994, así como los reportes de la ADI y sus trabajos preparatorios fueron transmitidos en su totalidad a la Organización de las Naciones Unidas para la Educación, la Ciencia y la Cultura (UNESCO), quien, el 2 de noviembre de 2001, adoptó la Convención sobre la Protección del Patrimonio Cultural Subacuático. Esta Convención representa la culminación del derecho internacional para la protección del patrimonio cultural sumergido, ya que reflejaba las expectativas y el consenso tanto de los Estados ribereños como las de los Estados con embarcaciones, con el objetivo primordial de proteger el patrimonio cultural subacuático en beneficio de la humanidad, haciendo especial énfasis en su preservación.

Sin embargo, aun cuando el trabajo realizado por la ADI fue transmitido en su totalidad a la UNESCO, el texto final de la Convención fue sustancialmente diferente al de la Convención de Buenos Aires de 1994. Lo anterior, producto de los grandes debates sostenidos entre los representantes, así como la falta de información de los propios países como lo demuestran los trabajos preparatorios de dicha Convención (Regan, 2005).

\section{La Convención sobre la Protección del Patrimonio Cultural Subacuático de la UNESCO}

La Convención de 2001 representa lex specialis, es decir, una norma referida específicamente al patrimonio cultural subacuático; es un instrumento autónomo de derecho internacional, dotado de un ámbito de aplicación propio y de un conjunto específico de disposiciones de fondo. Antes de 2001, ni el derecho internacional ni la legislación de los países trataban convenientemente el conjunto de cuestiones que se plantean en este terreno.

En la mencionada Convención, en efecto, se establece un notable compromiso entre el imperativo de la protección y las necesidades operativas, pues ninguna actividad relativa al patrimonio cultural subacuático, a la que se aplique la Convención, estará sujeta a las normas sobre rescates y hallazgos, a menos que esté autorizado por las partes competentes, esté en plena conformidad con la Convención y se garantice que toda operación de recuperación al patrimonio cultural subacuático se realice con la máxima protección de éste. 
Los trabajos para la Convención del 2001 iniciaron en 1993, año en el que el Consejo Directivo incorporó en la agenda de la Organización la defensa del patrimonio cultural subacuático como tema prioritario. Sin embargo, fue hasta noviembre de 1997, año en que el director general de la UNESCO, basado en un reporte, señaló que la protección del patrimonio cultural subacuático debía ser regulada a nivel internacional y que el método por adoptar debía ser el de una convención internacional. Tras años de debate, el texto final fue adoptado en la 31a. Conferencia de la UNESCO con 87 votos a favor, cuatro en contra (Rusia, Noruega, Turquía y Venezuela) y 15 abstenciones. La Convención de 2001 también incorpora un documento anexo denominado Normas Relativas a las Actividades Dirigidas al Patrimonio Cultural Subacuático, las cuales pretenden reglamentar el procedimiento para la protección.

El texto de la Convención pone fin a importantes discusiones sobre los derechos de propiedad de quienes hayan logrado el rescate exitoso de restos náufragos, al desconocerlo y otorgar en su lugar una recompensa económica por las labores realizadas. De la misma manera, siguiendo la temporalidad establecida en la Convención de Buenos Aires, establece una temporalidad específica para determinar la existencia de restos culturales, históricos y arqueológicos — por lo menos 100 años - y rechaza categóricamente la explotación comercial del patrimonio cultural subacuático. Particularmente, es interesante señalar cómo los conceptos de "temporalidad", "abandono" y "propiedad estatal" juegan un papel diverso en los países pertenecientes a la Commonwealth y los países pertenecientes a otras tradiciones jurídicas.

Los primeros han incorporado una mayor noción de prerrogativa soberana, la cual sugiere una propiedad residual a favor de los intereses de la Corona en todos los restos históricos, ya sea que se encuentren en aguas territoriales o en aguas internas pertenecientes al Estado costero. De tal manera que existe una fuerte presunción sobre la continua propiedad que el Estado guarda frente a ellos, es decir, se puede decir que estos barcos nunca se han abandonado. Esta noción tiene su fundamentación en la práctica estatal que dichos países llevan a cabo. Las legislaciones internas de estos Estados le han otorgado una mínima o nula protección a los restos marítimos que contienen un significado histórico o cultural. Sin embargo, la existencia de esa presunción es suficiente para otorgarle a la Corona derechos de propiedad sobre los restos. 
Por otro lado, los Estados Unidos han abandonado el concepto de prerrogativas soberanas, al afirmar que no existe presunción a favor de los derechos de propiedad que guarda el Estado sobre los restos marítimos. En el supuesto de que no exista propietario o ninguna persona muestre interés por los mismos, el Estado se encuentra en igualdad de posición para el reclamo de dicha propiedad. En estos casos, las cortes han aplicado el derecho de descubrimiento en la adjudicación de derechos de propiedad.

Por lo anterior, la falta de presunción a favor de los derechos de propiedad para los países ha obligado a los Estados Unidos a adoptar legislación doméstica para la protección de los restos dentro de sus aguas territoriales, con el objetivo de otorgar certeza con respecto a los restos históricos que deben ser monitoreados y protegidos como recursos arqueológicos, históricos y culturales. Tras varios debates, la Convención de 2001 trató de conciliar los diferentes criterios, reconociendo los derechos soberanos de cada Estado y estableciendo una temporalidad para el establecimiento del patrimonio cultural subacuático.

Otro de los pilares fundamentales de la Convención de la UNESCO radica en la protección del patrimonio cultural en la zona económica exclusiva, la plataforma continental y el alta mar, al establecer obligaciones de cooperación en estas zonas, de manera inédita a cualquier otro régimen internacional. ${ }^{15}$ De la misma trascendencia es la incorporación de la denominada "zona" al ámbito de aplicación de la Convención, la cual corresponde a los fondos marinos y oceánicos, y su subsuelo, fuera de los límites de la jurisdicción nacional.

Ahora bien, la cooperación internacional, los derechos y las obligaciones de cada Estado varían de acuerdo con el lugar en donde dichos restos son encontrados. Por un lado, en las aguas interiores, archipelágicas y en el mar territorial, el Estado, en ejercicio de su soberanía, puede reglamentar y autorizar las actividades dirigidas a la protección del patrimonio cultural subacuático. Por otro lado, en la zona económica exclusiva y en la plataforma continental esa reglamentación únicamente podrá llevarse a cabo cuando tenga por finalidad evitar una intromisión en sus derechos soberanos o en su jurisdicción.

15 Matsuura, Koïchiro, Commentary of UNESCO Director-General on the Ocassion of the Information Meeting on the Convention on the Protection of the Underwater Cultural Heritage, 2006. 
En ambos casos, el Estado tiene la obligación de informar a los demás Estados que mantengan un "vínculo verificable" o que "hayan declarado un interés" en dichos descubrimientos. El procedimiento reviste un mayor tecnicismo tratándose de descubrimientos hechos en la zona económica exclusiva y en la plataforma continental, ya que en estos casos el Estado descubridor tendrá la obligación de coordinar todas las medidas de protección y expedir autorizaciones a fin de proteger el patrimonio cultural; en este sentido, la Convención advierte que este Estado no actuará en nombre propio, sino en nombre de todos los Estados partes y en beneficio de toda la humanidad. Estos principios también serán aplicables a la franja denominada "zona".

No obstante el establecimiento de mecanismos efectivos, la Convención también incorpora el concepto de inmunidad soberana, el cual ha sido objeto de fuertes críticas. Este concepto sugiere que aquellos buques gubernamentales que gocen de inmunidad soberana, no estarán obligados a comunicar los descubrimientos hechos al patrimonio cultural subacuático, siempre y cuando dichos buques sean utilizados con fines no comerciales, realicen los descubrimientos en el curso normal de sus operaciones y no sean empleados con fines comerciales.

Sin embargo, aun cuando para estos buques tienen garantizado en todo momento libertad y seguridad, se encuentran obligados a trabajar en la investigación y coordinación de los descubrimientos. Tal y como lo apunta Luigi Migliorni, no existe una convención internacional ni ninguna otra regla de derecho consuetudinario internacional aplicable a este ámbito, y continúa diciendo que aun cuando se pudiera argumentar la existencia de opinio juris en esta sentido, no existe suficiente práctica estatal que soporte la existencia de dicha regla.

Finalmente, el texto anexo a la Convención - las denominadas normas relativas a las actividades dirigidas al patrimonio cultural subacuático- proporciona un ambicioso procedimiento para la protección del patrimonio cultural subacuático. Entre otros, obliga al Estado coordinador o descubridor a contar con el financiamiento suficiente para cumplir el proyecto de rescate en todas sus fases, incluyendo la conservación, la documentación y la preservación del material recuperado. Queda cuestionar cuántos países cuentan hoy en día con las capacidades técnicas-financieras para cumplir con las expectativas de todos los demás Estados partes de la Convención. 
No obstante el inédito esfuerzo, así como los largos debates sostenidos para su adopción, la Convención cuenta con una baja tasa de ratificación. No es de sorprender la adopción de un instrumento multilateral de las dimensiones de la Convención de la UNESCO de 2001. Los años de trabajo de otras organizaciones internacionales, así como el interés internacional en el patrimonio cultural, nos permiten entender su adopción. Sin embargo, esa misma inercia no permitió que los errores de otros instrumentos se ajustaran en el texto final, basta aplicar las críticas señaladas a otras disposiciones a lo largo de este capítulo a la Convención de la UNESCO.

Hoy en día, de los veinte países que se necesitan para que la Convención entre en vigor, únicamente 17 han depositado su instrumento. Habrá que estar atentos y observar los ajustes necesarios para que este buen propósito surta el efecto necesario en la comunidad internacional. ${ }^{16}$

\section{EL COMPLEJO TRAZADO DE UNA RUTA ALTERNATIVA. RESPUESTAS DEL DERECHO COMPARADO Y DEL DERECHO INTERNACIONAL MÁS ALLÁ DE LA APROXIMACIÓN CULTURAL}

El tratamiento de restos náufragos, diferentes al patrimonio cultural, posee de igual manera una aproximación reciente en el derecho internacional. Esta área reviste una naturaleza distinta a la estudiada anteriormente, ya que las reglas de remoción en el derecho internacional se enfocan a brindar condiciones seguras a la navegación, así como evitar la contaminación de los mares. Ha sido en años recientes que, la responsabilidad de los gobiernos de cumplir con dichas obligaciones se ha incrementado considerablemente, por lo cual la legislación nacional muestra avances significativos en este segundo aspecto fundamental para el derecho internacional.

A nivel interno, los gobiernos han implementado mecanismos para otorgar un marco jurídico apropiado a la remoción de restos y la recuperación de gastos efectuados por esta actividad. Es así como, antes de la culminación de instrumentos internacionales, los países habían incluido en sus instrumentos nacionales los siguientes conceptos: definición de

16 Vialard, Antoine, op. cit., nota 2, pp. 53 y ss.; Baughen, Simon, op. cit., nota 2, p. 319; Gilmore, Grant, op. cit., nota 2, pp. 689 y ss.; Healy, Nicholas et al., op. cit., nota 2, pp. 763 y ss. 
restos náufragos, parámetros específicos para determinar cuándo constituyen un peligro, responsabilidad para los propietarios, y los costos relacionados con la remoción. ${ }^{17} \mathrm{La}$ labor del derecho internacional se ha centrado en la unificación de los criterios existentes en la práctica estatal, y el establecimiento de derechos y obligaciones para los Estados, una coordinación más estrecha con gobiernos extranjeros, y delimitar la actuación de los grupos de salvaguarda. Sin embargo, este segundo aspecto fundamental va más allá, ya que se requiere también de la actuación del individuo como propietario de los restos marítimos, que por su carga, puedan constituir un peligro para el medio ambiente y la navegación. Particularmente, el derecho internacional tiene la tarea de establecer derechos y obligaciones relativos a la identificación, reportes, localización y remoción de restos peligrosos, específicamente aquellos que se encuentren más allá de las aguas territoriales.

Al igual que con el patrimonio cultural, el fin de la Segunda Guerra Mundial representa un parte aguas en el interés sobre la remoción de restos náufragos y su impacto al medio ambiente, debido a que muchos de los buques empleados durante ese periodo representan una amenaza latente al medio ambiente por los residuos de hidrocarburos y municiones que contienen. Los esfuerzos para dar una respuesta apropiada a esta amenaza se complica al considerar factores como la edad del buque, el potencial explosivo y los posibles daños ocasionados durante la remoción.

Por lo anterior, el establecimiento de normas internacionales orbita en torno a las siguientes cuestiones: ¿cuándo es posible declarar la existencia de un resto náufrago?, ¿a quién le corresponden los derechos de propiedad una vez que el resto ha sido removido?, ¿quién debe pagar los costos de recuperación del resto?, ¿es únicamente el propietario del resto náufrago el responsable de dicha remoción?

El interés de la comunidad internacional tampoco es motivo de asombro, ya que durante años recientes se han registrado pérdidas catastróficas de buques con carga de hidrocarburos. ${ }^{18}$ Estos eventos, así como el potencial incremento en el número de buques sumergidos, atrajeron la atención de los gobiernos sobre la adopción de mecanismos eficaces para

17 Comité Legal de la Organización Marítima Internacional, 75/6/2, 14 de febrero de 1997, Convención sobre la Remoción de Restos Náufragos Materiales.

18 Tal es el caso del M/T Prestige, M/T Erika, M/T Tricolor y el M/T levoli Sun. 
responder a los retos energéticos del futuro. Los gobiernos actúan una vez que las reservas mundiales de petróleo escasean. Esos descubrimientos han demostrado el potencial energético que guardan algunos buques sumergidos en aguas profundas, tal es el caso del Prestige (España), el Erica (Francia) y el Nakhodka (Japón). ${ }^{19}$ Sin embargo, las operaciones de rescate de buques petroleros involucran una serie de factores caracterizados por su alto nivel de complejidad. Las acciones de rescate se basan en un análisis del costo-beneficio de la operación, el cual involucra, a su vez, desarrollo del área geográfica en donde se pretenden realizar las operaciones, el valor de la carga, y el potencial daño ambiental.

Por lo anterior, las organizaciones internacionales, principalmente la Organización Marítima Internacional (OMI), han centrado sus actividades en trazar las directrices para la remoción de restos náufragos; ${ }^{20} \sin$ embargo, antes de estudiar el trabajo de dicha organización, vale la pena echar un vistazo a las tratados multilaterales que abordan indirectamente la remoción de restos náufragos, así como a las legislaciones nacionales de algunos países.

\section{Convemar: un enfoque holístico, pero inacabado}

La Convemar es el tratado multilateral que regula, de manera indirecta, la remoción de restos náufragos. Los principios establecidos en este instrumento giran en torno a la soberanía y jurisdicción de los Estados en la remoción de dichos restos. Así, la Convención se aplica en dos zonas distintas establecidas: dentro de las 12 millas del mar territorial, en donde el Estado costero tiene jurisdicción sobre los restos marítimos, y fuera de las aguas territoriales, en donde se aplica el principio de la libertad del alta mar.

Dentro del mar territorial, las aguas internas y las aguas archipelágicas, los Estados mantienen jurisdicción exclusiva sobre los restos marítimos, sean o no de naturaleza arqueológica. Aunque existe una obligación de los barcos extranjeros de no entorpecer el paso inocente, los Estados

19 Helton, Douglas, Wreck Renoval: a Federal Perspective, Office of Response and Restoration National Oceanic and Atmospheric Administration, Seattle, Washington, 2003.

20 El proyecto de la OMI sobre remoción de restos náufragos se estudiará en el apartado VI de este documento. 
costeros tienen, a su vez, la obligación correspondiente de no impedir tal paso. En este sentido, esta obligación puede requerir la remoción de restos marítimos que se encuentran parcialmente sumergidos o que cuenten con una profundidad tal que impidan la libertad a la navegación. Hasta que la remoción de un resto sea efectuada, los Estados costeros mantienen la obligación de informar hasta qué punto los restos pudieran constituir una amenaza para la navegación.

Además, los Estados costeros tienen la posibilidad, en determinados casos, de adoptar leyes y medidas tendentes a brindar seguridad a la navegación y regular el tráfico marítimo. Estas medidas pueden llamar a la restricción del paso inocente y así evitar, en lo posible, la existencia de restos de marítimos náufragos. Sin embargo, los Estados costeros tampoco pueden entorpecer el paso inocente, su obstrucción constituye una excepción a la regla y será únicamente válida en la medida en que la seguridad del Estado así lo requiera. Dentro de la plataforma continental, los Estados mantienen derechos de exploración y explotación de los recursos naturales, sin embargo, existen pocas bases para reclamar la jurisdicción en la remoción de los restos marítimos. ${ }^{21}$

Más allá de las 12 millas náuticas del mar territorial se aplica el principio de la libertad de los mares. En esta zona se presentan conflictos relacionados con la propiedad de los restos, así como el lugar en donde se resolverán las disputas que se originen con motivo de dicha actividad. Sin embargo, se dice que aun cuando la Convemar no limita la libertad de los mares de manera expresa, una interpretación armónica con el resto de sus disposiciones, establece restricciones al ejercicio de dicha soberanía.

Lo anterior tiene como base las disposiciones relativas a la zona económica exclusiva: primero, los Estados tienen soberanía en la explotación y exploración, conservación y mantenimiento de los recursos naturales; segundo, dicha soberanía no es exclusiva, ya que la jurisdicción en la solución de conflictos en dicha zona deberá ser resuelta en las bases de equidad y respeto de los intereses de la comunidad internacional como un todo. Los conflictos que surjan con motivo de la remoción de restos náufragos en esta zona deberán sujetarse, de igual manera, a las reglas de equidad y respeto en los intereses de la comunidad internacional.

21 Estados, como Australia, Irlanda, Noruega, Portugal y España han emitido legislación para esta jurisdicción. 
En la franja conocida como el patrimonio común de la humanidad se aplica el principio de la libertad de los mares para la remoción de restos diferentes a los de naturaleza histórica o arqueológica.

\section{Comentarios de derecho comparado}

La implementación de mecanismos a nivel nacional recorrió un largo camino, reflejado, primeramente, en distintas convenciones internacionales relacionadas con hipotecas y préstamos marítimos tales como las convenciones de 1962, 1967 y 1993. La primera de estas convenciones, a pesar de no enlistar cada una de las acciones que pudieran instituirse con motivo de la remoción de restos náufragos, reconoció la posibilidad de cada Estado de establecer legislación interna relativa a dichas actividades. ${ }^{22}$

Este criterio fue rechazado por la Convención de 1967 al señalar que la remoción de restos náufragos debía ser considerada como una deuda marítima. Finalmente, la Convención de 1993 retomó el criterio de 1962, al retirar de la lista de deudas marítimas las relacionadas con la remoción de restos náufragos y permitir que dicha acción fuera regulada por leyes locales.

Sin embargo, aun cuando este criterio deja a la discreción del Estado el determinar las directrices y posibles acciones por la remoción, establece que ésta deberá ser únicamente para garantizar la seguridad en la navegación, es decir, deja fuera la remoción de restos náufragos para otros propósitos. ${ }^{23}$ Estos criterios han influido en el derecho interno de los Estados como se señala a continuación.

\section{A. Estados Unidos de América}

El marco jurídico de la remoción de restos náufragos cuenta con importantes avances legislativos en este país. Desde hace un par de décadas, los Estados Unidos han implementado una completa maquinaria legislativa y administrativa sobre los derechos de propiedad y costos de

22 Francia, Estado parte de la Convención, con base en el Protocolo Adicional de la misma, declaró que los gastos relacionados con las reclamaciones de remoción deberían tener un privilegio respecto al valor del resto náufrago.

23 Tetley, William, "Special Legislative Rights and Wreck Removal”, Lousiana Law Review, 55 La. L. Rev. 861, 1995. 
remoción. Aun cuando la materia de remoción corresponde a una actividad meramente federal, no existe una entidad exclusiva facultada para llevarla a cabo. Algunas de las principales entidades son: US Army Corps of Engineers, US Coast Guards, US Department of Interior, US Environment Protection Agency, National Oceanic and Atmospheric Administration.

Sin embargo, ninguna agencia federal desea, por sí sola, llevar a cabo la remoción de restos náufragos abandonados, a menos que dicha función sea encomendada con base en un mandato, cuente con el financiamiento y con el personal adecuado, y realice dichas actividades dentro de un marco jurídico sólido. ${ }^{24}$

La legislación estadounidense establece que la remoción de restos náufragos es una actividad federal, y considera ilícito obstruir, mediante artefactos, las aguas navegables. De igual manera, faculta al secretario de la Armada para destruir o remover y vender los restos náufragos aun cuando el propietario del barco haya sido o no negligente o responsable por la obstrucción.

Así es posible advertir dos importantes periodos dentro de la legislación estadounidense: el periodo anterior a 1986 y el periodo posterior a esa fecha. En el primer periodo, un propietario no negligente no era responsable por los costos de la remoción después del abandono. Después de 1986, los costos de la remoción correrán a cargo del propietario de la embarcación haya o no actuado con negligencia, este criterio quedó asentado en el Acta de Restos Náufragos de 1987, en donde se establece que los Estados Unidos tienen título de propiedad sobre los restos encallados o sumergidos.

La remoción de restos náufragos se da también cuando los restos hayan sido abandonados. Una vez que el secretario de la Armada ha notificado al propietario de los restos sobre la remoción, y éste no ha retirado el barco en un lapso de 30 días, se entiende que el bien ha sido abandonado. Sin embargo, las sentencias de los tribunales estadounidenses demuestran que la noción de abandono es considerada como una cuestión de hecho. ${ }^{25}$

Es así como, la relación entre el gobierno de los Estados Unidos y los propietarios, respecto a la recuperación de los gastos de remoción, puede 
estructurarse como se sugiere a continuación: (i) Cuando el propietario del barco no es negligente por el estancamiento del artefacto en el agua, el gobierno (por conducto del secretario de la Armada), después de un abandono de 30 días, deberá destruir o remover los restos náufragos. Tiene también la posibilidad de iniciar los procedimientos para la venta de los mismos dentro de la Tesorería, por lo cual se le asegura al gobierno prioridad sobre cualquier otro acreedor. En una situación de emergencia, el secretario de la Armada deberá actuar aun cuando el propietario no haya dado aviso dentro de los 30 días siguientes a la notificación. (ii) Cuando el propietario de la embarcación es negligente por el estancamiento en las rutas de agua, el gobierno de los Estados Unidos después del abandono o de la noticia de los 30 días, o inclusive menos, deberá remover los restos o venderlos, y el procedimiento deberá ser llevado a cabo por la Tesorería, por lo cual el gobierno mantiene preferencia sobre la venta de la remoción para recuperar los gastos de dicha remoción.

Si los fondos derivados de la venta no son suficientes para pagar los costos de la remoción, el gobierno estadounidense podrá iniciar acciones en contra del propietario negligente para equilibrar los gastos efectuados por la remoción.

En ambos casos, el gobierno de los Estados Unidos podrá iniciar acciones en contra de terceros que hayan sido negligentes en contra de la parte proporcional que éstos guarden frente a los restos, de conformidad con los gastos empleados en la remoción.

Adicionalmente, la remoción de restos náufragos no sólo corresponde a una actividad gubernamental, los particulares la llevan a cabo mediante las actividades de salvamento. Los particulares podrán, de igual manera, reclamar los gastos efectuados con motivo de la remoción, sin importar que el propietario de los restos sea o no negligente.

Finalmente, el Acta Fuera de la Plataforma Continental (Outer Continental Shelf Act) establece que la autoridad de la Secretaría de la Armada para prevenir la obstrucción de la navegación en aguas navegables se extiende a islas artificiales, instalaciones y otros componentes fuera de la plataforma continental.

\section{B. Reino Unido de Gran Bretaña e Irlanda del Norte}

Reino Unido muestra también avances significativos en su legislación local. Aquí, encontramos diferencias respecto al régimen aplicable 
en los Estados Unidos, ya que los gastos de remoción en la legislación británica sí dependerán de la actitud del propietario. Por un lado, en caso de abandono, el propietario no negligente podrá eximir su responsabilidad personal frente a la autoridad portuaria, hasta antes de que se efectúen los gastos de la remoción. Por otro lado, el propietario no se exime de dicha responsabilidad cuando la obstrucción es causada por su negligencia conforme a los criterios del common law.

Uno de los aspectos más novedosos es el criterio establecido en la regulación de la actuación portuaria, ya que tiene la obligación de remover los restos de manera razonable y cuidadosa: debe actuar con diligencia durante toda la actividad, asimismo debe probarse que la acción es necesaria, de lo contrario, la autoridad podría ser responsable frente al propietario por los daños ocasionados a la propiedad durante la remoción. Las autoridades portuarias podrían ser también responsables por negligencia cuando no se ha demostrado un cuidado razonable en el cumplimiento de sus obligaciones en garantizar la seguridad en la navegación libre de obstrucciones en las aguas dentro de su jurisdicción.

\section{Canadá}

El Acta de Protección de las Aguas Navegables faculta al gobierno de Canadá para remover o destruir cualquier resto náufrago, incluidos barcos, partes del barco o carga que obstruya cualquier agua navegable de Canadá. De igual manera, tanto el barco como la carga pueden ser vendidas por el gobierno, mediante subasta o cualquier otro medio, para recuperar los gastos relativos al mantenimiento, destrucción, remoción y venta.

Por lo tanto, el gobierno, claramente, cuenta con posibilidad de acción en contra del dueño de la embarcación, el operador propietario, experto, o cualquier otra persona encargada del barco, así como en contra de quien sea responsable por el abandono del resto marítimo.

Resulta también interesante que Canadá cuente con una legislación especial relacionada de manera específica con la prevención de la contaminación en los mares. The Artic Waters Pollution Prevention Act autoriza al gobierno de Canadá para llevar a cabo la remoción de cualquier resto encallado o abandonado, así como su carga. El Acta autoriza la remoción aun cuando las aguas canadienses de 60 grados de latitud norte, sean, o puedan llegar a ser, contaminadas por los depósitos de los restos. 
Ahora bien, aun cuando no existe un derecho especial legislativo por el despojo y la venta de los barcos por contaminación, sí existe un derecho definitivo de acción por el gobierno para recuperar los gastos de remoción.

\section{RECEPCIÓN NACIONAL. REGULACIÓN Y POLÍTICAS PÚBLICAS EN MÉXICO}

\section{Regulación}

La regulación mexicana en materia de remoción de restos náufragos debe entenderse desde tres perspectivas: (i) de inspección técnico-administrativa, (ii) de prevención y control de la contaminación marítima, así como de (iii) amarre, abandono y desguace de embarcaciones.

Si bien los primeros dos son de importancia, es en el tercer sector donde el legislador mexicano ha buscado encontrar respuestas para los problemas logísticos de los puertos nacionales, al haber tantas embarcaciones abandonadas sin mucho por esperar de los armadores.

La ley de la materia, la Ley de Navegación y Comercio Marítimos (LNCM), de 2006, ha pretendido dotar de mayores herramientas normativas a la Dirección General de Marina Mercante - y a los capitanes de puerto - como autoridad marítima, para poder "limpiar", mediante remociones ordenadas, la gran variedad de embarcaciones abandonadas de puertos mexicanos.

Por una parte, la LNCM pretende tomar una actitud preventiva ante el crecimiento de embarcaciones a abandonar en puertos mexicanos. Así, a partir del artículo 87, regula las autorizaciones de amarre temporal, el procedimiento a seguir y las condiciones impuestas, incluida la garantía que debe otorgar el propietario o naviero en cuestión.

El plazo de amarre temporal no puede ser de más de 30 días hábiles contados a partir de la notificación de la autorización, pudiendo renovarse en una ocasión. Transcurrido ese plazo, si no se pusiere en servicio la embarcación; o bien, cuando antes de este término estuviere en peligro de hundimiento o constituya un estorbo para la navegación u operación portuaria, la capitanía de puerto por sí misma, o a solicitud de la administración portuaria, ordenará su remolque al lugar que convenga a esta última. 
Ahora bien, si no se cumpliere la orden, la capitanía de puerto coordinará la maniobra por cuenta del propietario de la embarcación. Después, decretará el ejercicio del derecho de retención, hará la declaratoria de abandono, procederá al trámite de ejecución de la garantía, y, en su caso, al remate de la embarcación por entero o mediante desguace.

El remate de la embarcación se tramitará siempre que no se haya otorgado garantía, o cuando existiendo no sea suficiente para pagar el costo de las maniobras, los daños y perjuicios ocasionados o que puedan generarse, así como todos los adeudos pendientes a liquidar.

Ahora bien, la capitanía de puerto declarará el abandono de las embarcaciones a favor del Estado, en diversos casos, entre los que podemos destacar: (i) si permanece en puerto sin realizar operaciones y sin tripulación, durante un plazo de 10 días hábiles, y sin que se solicite la autorización de amarre temporal; (ii) cuando fuera de los límites de un puerto se encuentre en el caso anterior, el plazo es de 30 días hábiles; (iii) cuando hubieren transcurrido los plazos de amarre temporal y de prórroga, sin que la embarcación sea puesta en servicio; (iv) cuando quede varada o se fuere a pique, sin que se lleven a cabo las maniobras necesarias para su salvamento en el plazo establecido.

Como última pieza del eslabón se encuentra el desguace. Éste se autoriza por el capitán de puerto, previa dimisión de bandera — cuando este trámite es posible, según veremos en las políticas públicas al respectocontando con la opinión favorable de la autoridad ambiental competente en el lugar y plazo determinado, siempre y cuando no perjudique la navegación y los servicios portuarios, se cuente con un programa de trabajo y se compruebe plenamente la propiedad de la embarcación. Lo anterior, previa baja de matrícula y en su caso, constitución suficiente de garantía para cubrir los gastos que pudieran originarse por daños y perjuicios en las vías navegables, a instalaciones portuarias y al medio marino, gastos por salvamento de la embarcación o la recuperación de sus restos, así como los derivados de la limpieza del área donde se efectúe la operación.

\section{Políticas públicas}

Si bien la declaratoria de abandono faculta al Estado para remover la embarcación en cuestión, en México no se había generado un programa integral de remoción de embarcaciones varadas, hundidas y semihundidas, sino hasta el 2004. A la par de la SCT, la Sagarpa implementó un 
programa llamado de esfuerzo sobre embarcaciones pesqueras abandonadas.

Con motivo de la elaboración de este artículo, nos dispusimos, mediante los mecanismos de transparencia del Gobierno federal, a detectar el estado de la cuestión, tanto con relación a lo que se ha hecho para limpiar los puertos mexicanos de embarcaciones hundidas - total o parcialmente - y varadas, como lo que hace el gobierno para prepararse para la eventual entrada en vigor del Convenio de Nairobi.

Pues bien, en febrero del 2004, la SCT presentó un informe consolidado de los reportes de las capitanías de puerto en todo el país. Del reporte aparecen decenas de embarcaciones en distintas situaciones, tanto físicas como jurídicas. A partir de ese recuento, la SCT elaboró el llamado Programa de Limpieza de Puertos, en el cual, en la medida de lo posible, se trataba de encontrar a los propietarios, navieros o agentes de embarcaciones varadas o hundidas en las aguas portuarias, para requerirles la remoción. ${ }^{26}$

En esencia, los requerimientos instrumentados por las capitanías de puerto en todo México consideraban, en el contexto de la LNCM del 2006: (i) ordenar la remoción a cuenta del propietario o naviero; (ii) en su caso, ordenar el desguace en el mismo sentido; (iii) de no proceder así, entonces la propia SCT se encargaría de estas acciones, mismas que serían pagadas de la venta - previa tramitación administrativa o judicial— de la embarcación.

Para el caso de una reacción positiva de los propietarios o armadores, la SCT expedía una autorización de desguace, en donde se imponían una serie de condiciones, entre las cuales destacan: (i) un programa de trabajo para la operación; (ii) el pago de derechos conforme a la Ley Federal de Derechos; (iii) la prohibición de arrojar lastre, escombros o basura, así como derramar o verter petróleo o sus derivados, aguas residuales de minerales u otros elementos nocivos o peligrosos de cualquier especie, que ocasionen daños o perjuicios en aguas de jurisdicción mexicana; (iv) la presentación de una fianza; y (v) la presentación de un certificado libre de gases.

Como complemento al Programa de Limpieza de la SCT, la Sagarpa-Conapesca elaboraron en el 2005 su propio plan en el contexto del

26 Véase SCT, CGPMM, Dirección General de Marina Mercante, Dirección de Navegación, oficio del 11 de febrero de 2004. 
Programa de Acuacultura y Pesca. El plan pretendía ofrecer apoyo para la reducción del esfuerzo pesquero. El plan fue aplicado especialmente a los camaroneros de mediana altura. El plan detectó más de 150 embarcaciones que calificaban para remoción y desguace. ${ }^{27}$

Finalmente, si bien la SCT no ha dado a conocer — ni informado avances parciales - sobre un programa de implementación de la Convención de Nairobi, se espera que, en el contexto del proceso de ratificación, la SCT articule los aspectos de certificación que impone la Convención. De igual manera, se prende que la SCT intensifique su labor de limpieza de puertos, no solamente teniendo como instrumento la LNCM, sino, en caso de aplicar, por razón de su ámbito de validez, la propia Convención de Nairobi.

\section{LA CONVENCIÓN DE NAIROBI. UN TRATAMIENTO INTEGRAL A UN PROBLEMA CONTEMPORÁNEO}

\section{Antecedentes}

Hasta antes de la firma de la Convención de Nairobi sobre Remoción de Restos Náufragos, es posible afirmar que no existían principios generales internacionales relativos a las modalidades de la propiedad o abandono en las aguas soberanas de los Estados. Fue el 23 de mayo de 2007 cuando la Organización Marítima Internacional concluyó la Convención sobre Remoción de Restos Náufragos, conocida como la Convención de Nairobi.

El trabajo de la OMI comenzó en 1974 cuando el Comité Jurídico de la OMI hizo una revisión a las legislaciones locales de los Estados miembros que contaran con instrumentos internos relacionados con la remoción de restos náufragos; el objetivo de este trabajo era concluir un instrumento armónico de carácter internacional, sin embargo, el instrumento deseado no pudo concluirse. Fue hasta 1993, en la 69a. sesión, que el Comité Jurídico de la OMI retomó el tema de la remoción de restos náufragos a petición de Alemania, Grecia, Países Bajos y el Reino Unido. 
En la siguiente edición, nuevamente por petición de Alemania, los Países Bajos y el Reino Unido, la Organización incorporó en su agenda el tema de la remoción de restos náufragos. Dichos países enfatizaron la importancia de concluir un instrumento internacional y establecer reglas uniformes para la operación de remoción en aguas internacionales. De igual manera, estos tres Estados afirmaron que su mayor preocupación giraba en torno a las siguientes cuestiones: (i) los problemas de navegación originados por los buques que utilizan sus puertos, y (ii) los peligros de contaminación originados, de igual manera, por dichos buques. Los impulsores de este proyecto señalaron que la implementación de parámetros precisos y directrices a nivel internacional estaría de conformidad con el artículo 221 de la Convemar, al establecer directrices precisas, subsanar lagunas legales y armonizar los derechos de los Estados costeros.

Durante tres años, el Comité Jurídico trabajó activamente en el establecimiento de un instrumento internacional mediante la elaboración de reportes y cuestionarios. Particularmente, el Comité estudió, en su 74a. reunión en 1996, un reporte que afirmaba que el régimen nacional para la remoción de restos náufragos dentro de las aguas territoriales contaba con tantas similitudes que su inclusión en el documento final debía considerarse ampliamente. Durante este periodo, la agenda de la Organización se enfocó al cuidado del medio ambiente. Particularmente, se dijo que la OMI continuaría con su impecable participación a nivel internacional en materia ambiental, mediante la formulación de criterios precisos y el estudio de todas las fuentes de contaminación marítima y atmosférica, relacionadas con las operaciones marítimas. En este contexto, por tanto, la Convención debía ser considerada como otra piedra angular en el esfuerzo de la OMI para dirigir a la sociedad en la toma de medidas para el cuidado del frágil ambiente marítimo.

El secretario general de la OMI, Efhtimios E. Mitropoulos, afirmó que una vez adoptada y en vigor, la Convención sobre Remoción cubriría un vacío en el derecho internacional al proveer un marco jurídico legal adecuado para los Estados en las actividades de remoción, específicamente las llevadas a cabo en la zona económica exclusiva, ${ }^{28}$ respecto a

28 Como se estudiará más adelante, el ámbito de aplicación de la Convención representa uno de los aspectos más novedosos en lo que a remoción de restos náufragos respecta. 
restos que pudieran constituir un peligro para la navegación o que, por la naturaleza de su carga, amenazaran las vías marítimas o el Estado costero o la comunidad internacional en su conjunto.

Es así que la Organización tuvo como objetivo abordar la elaboración de reportes relacionados con los siniestros ${ }^{29}$ que originaron restos, los avisos para los operadores y demás Estados costeros respecto a la existencia de dichos restos, las acciones empleadas por los Estados costeros para su localización, los medios para determinar la peligrosidad del mismo de acuerdo con criterios específicos — tales como la profundidad de las aguas en donde se encontraran y la proximidad de las rutas de navegación-, los derechos y las obligaciones derivados de la remoción — delimitar la actuación de los propietarios y la del Estado_-, la contratación de seguros, las acciones que pudieran llevarse a cabo para exigir compensación y el arreglo de las disputas con motivo de dicha actividad.

\section{La Convención}

\section{A. Ámbito espacial de validez}

El artículo 1o. de la Convención señala como zona de aplicación del Convenio la zona económica exclusiva de un Estado parte, de conformidad con el derecho internacional, y cuando el Estado no haya establecido dicha Zona, será un área situada más allá del mar territorial de dicho Estado y adyacente a éste, y de una extensión que no supere las $200 \mathrm{mi}$ llas marinas contadas desde la línea de base a partir de las cuales se mide la anchura de su mar territorial. Tal y como lo advirtió el secretario general de la OMI, la Convención satura lagunas jurídicas creadas por otros instrumentos al establecer de plano dentro del ámbito de aplicación la ZEE.

De igual manera, resulta importante resaltar la posibilidad que tienen los países de ampliar el ámbito de aplicación de la Convención de conformidad con el artículo 3o. de la misma. Este artículo señala en su párrafo segundo que el Estado podrá aplicar la Convención a los restos encontrados en su mar territorial; dicha ampliación deberá llevarse a cabo mediante un procedimiento establecido, de igual manera, en el numeral 3,

29 El término siniestro marítimo fue presentado por una nota del gobierno mexicano el 8 de marzo de 2007. 
segundo párrafo. En cualquier caso, la aplicación del Convenio a los restos de naufragio en el territorio del Estado, incluido su mar territorial, no podrá ir en perjuicio de los derechos y las obligaciones de ese Estado de adoptar medidas respecto a los restos de naufragio siempre que no se refieran a la localización, balizamiento y remoción de conformidad con la Convención de Nairobi.

\section{B. Definición de resto}

A este respeto, la Convención no sólo incluyó en la definición de resto los buques varados o hundidos, cualquier parte de los mismos, los objetos del buque que hayan caído al mar, se encuentren varados, hundidos o a la deriva, sino también cualquier buque que está a punto de hundirse o de quedar varado, o del que se espera razonablemente que pueda hundirse. Habrá que esperar la interpretación judicial, así como los requisitos técnicos necesarios para delimitar la aplicación del término razonable.

Los buques de guerra, así como los buques propiedad de los Estados que sean utilizados para fines no comerciales se encuentran fuera de la aplicación de la Convención, siguiendo el principio de la inmunidad soberana.

\section{Derechos y obligaciones de los Estados}

Asumiendo que los oficiales gubernamentales han estudiado estos factores y han determinado que el resto representa un peligro para la navegación, todos los derechos y las obligaciones establecidas se ponen en práctica. La Convención establece que únicamente será necesario que el Estado afectado tenga noticia sobre la existencia de dichos restos en el área de la Convención (sin que se haya tenido aviso del operador o del master, inclusive) para que la obligación de prevenir a los demás Estados exista.

\section{La existencia de un peligro}

La siguiente obligación será determinar si el resto representa un peligro para el Estado costero, en este punto, si se determina que el resto no constituye tal, la Convención dejará de aplicar. La delimitación de este término condujo grandes horas de debate en la Organización, el factor 
determinante será el perjuicio o impedimento para la navegación o que pueda resultar en un detrimento para el medio ambiente marino o para los intereses del Estado costero o de la comunidad internacional.

Como era de esperarse, la Convención también precisa importantes requisitos técnicos para determinar la existencia de un peligro, tales como la proximidad a las rutas de navegación, el tipo de tráfico, la vulnerabilidad de las instalaciones portuarias, etcétera. La Convención no señala si estos requisitos son acumulativos, también deja al arbitrio de los Estados parte la incorporación de otros. Nuevamente, corresponderá a los órganos judiciales establecer la primacía de los mismos para el establecimiento de un peligro.

\section{E. Remoción de restos}

Las obligaciones relacionadas con la localización de restos náufragos ponen fin, por primera vez, a discusiones importantes relacionadas con el aviso que debe darse a los demás Estados interesados sobre la existencia de dichos restos. Estas obligaciones dan una respuesta formal a las actividades de remoción en las costas de Europa, específicamente, en la zona de los Balcanes y en el Mediterráneo, en donde un gran número de Estados podrían resultar afectados por la existencia de restos náufragos que se encuentra fuera de sus costas (tal y como ha sucedido en el pasado).

Lo anterior explica por qué la obligación establecida en el artículo 10 posiciona al Estado afectado el consultar con otros Estados que también pudieran estar interesados en la remoción. También explica por qué, en la elaboración de una definición de Estado afectado, se decidió otorgarle al Estado en cuya área se encuentra físicamente el resto, un papel principal para el manejo del barco, aun cuando, en la práctica, pudiera considerarse que el resto representa una amenaza mayor para otros Estados.

La Convención establece que la responsabilidad de remover el resto corresponde en primer lugar al propietario inscrito, el cual, también, es responsable de los costos de localización, balizamiento y remoción de los restos. El Estado afectado puede establecer las condiciones y el tiempo límite para que dichas actividades se lleven a cabo; si no se respeta ese tiempo, el Estado puede llevar a cabo la remoción por sí mismo y recuperar mediante acciones los costos de la operación. 
Las hipótesis sobre las cuales el propietario puede eximirse de dicha responsabilidad también están contempladas dentro de la Convención. ${ }^{30}$ De igual manera, el propietario presentará la contratación de seguros, ${ }^{31} \mathrm{u}$ otra garantía financiera a la autoridad competente del Estado, podrá limitar su responsabilidad en virtud de cualquier régimen nacional o internacional, y se encuentra en libertad de contratar los servicios de rescate o cualquier otra persona para que lleve a cabo dicha remoción.

A este respecto, es importante resaltar las observaciones realizadas por el Grupo Internacional de Asociaciones de Protección e Indemnización, la Cámara Naviera Internacional y Bimco sobre la responsabilidad del propietario inscrito. Las organizaciones afirmaron que el modelo presentado por el Comité Jurídico de la OMI no seguía el modelo de las disposiciones correspondientes de los instrumentos internacionales sobre responsabilidad e indemnización ya adoptado por la organización, ${ }^{32}$ en cada uno de esos instrumentos se disponía la responsabilidad objetiva del propietario e incluían una disposición según la cual no podría promoverse contra el propietario ninguna acción de reclamo que no se ajustara al instrumento.

De acuerdo con este texto, los conceptos de la responsabilidad objetiva, pero limitada del propietario inscrito, y del derecho de los reclamantes de proceder directamente contra el asegurador o el proveedor de la garantía financiera "han sido desarrollados por la Organización para facilitar la pronta indemnización de los reclamantes sin necesidad de controversias jurídicas que podrían ser largas y costosas". El texto final de la Convención tomó este criterio y lo incorporó en el artículo 10, párrafo 3, de la misma.

30 A este respecto, la Convención incorporó como base de la responsabilidad la negligencia del propietario, por lo cual rechazó el criterio establecido en las leyes federales de los Estados Unidos.

31 El gobierno de los Estados Unidos pidió que los requisitos relativos a la contratación de seguros no se incorporaran al texto final de la Convención ya que, en su opinión, dicha obligación no formaba parte del derecho consuetudinario internacional.

32 A saber, el Convenio Internacional sobre Responsabilidad Civil Nacida de Daños Debidos a Contaminación por Hidrocarburos (1992), el Convenio Internacional sobre Responsabilidad e Indemnización de Daños en Relación con el Transporte Marítimo de Sustancias Nocivas y Potencialmente Peligrosas (1996), y el Convenio Internacional sobre Responsabilidad Civil Nacida de Daños Debidos a Contaminación por los Hidrocarburos para los Combustibles de los Buques (2001). 
Finalmente, las medidas incorporadas por el Estado afectado deberán ser proporcionadas al peligro. Igualmente, habrá que esperar como se determina en la práctica, mediante el estudio de sentencias nacionales principalmente de Canadá.

\section{F. Obligaciones financieras}

Los Estados presentes durante los debates de la Convención concluyeron que era indispensable contar con los recursos económicos suficientes para pagar los gastos relacionados con dicha actividad.

En este contexto, no es de asombrarnos que países como el Reino Unido, Estado parte de la Convención sobre responsabilidad originada por reclamaciones de derecho marítimo de 1976, han declarado reservas respecto al derecho que tiene el propietario de limitar el pago de la remoción. Sin embargo, estas obligaciones financieras deberán armonizarse con las referentes a la contratación de seguros.

Dentro de la Convención, los propietarios tienen posibilidad de asegurar los costos de la remoción en una cantidad igual a la relacionada con los límites de la responsabilidad de acuerdo con la Convención de 1976. Por lo cual una de las consecuencias en la aplicación de dicha disposición sería, por ejemplo, dentro de la legislación inglesa, que el propietario registrado pueda limitar los gastos relacionados con la remoción y contratar seguro por la cantidad igual a dicha remoción.

Así, es importante enfatizar los siguientes aspectos, primero, el acreedor puede iniciar los procedimientos respectivos y exigir la compensación debida en los términos de la Convención, ya sea, directamente, en contra del asegurador o cualquier otra persona que brinde las garantías financieras respectivas relacionadas con la responsabilidad del propietario registrado. Segundo, en ese caso, el demandado podrá invocar los medios de defensa que hubiese podido invocar el propietario inscrito, incluyendo la limitación de la responsabilidad de acuerdo con cualquier régimen nacional o internacional aplicable. También podrá hacer valer como medio de defensa que el siniestro marítimo haya sido ocasionado por la conducta dolosa del propietario inscrito, aunque no podrá invocar ningún otro de los medios de defensa que le hubiera sido posible invocar en una demanda presentada por el propietario inscrito del buque en contra de su persona. 


\section{G. Prescripción para el reclamo de los costos}

El artículo 13 establece que los derechos originados con motivo de la compensación se extinguen en un periodo de tres años, contados a partir de la fecha en la que se determinó el riesgo de conformidad con las disposiciones de la Convención.

\section{La Convención de Nairobi y su relación con la Convemar}

Los redactores de la Convención estaban conscientes que algunas de las obligaciones y derechos reconocidos para los Estados se encontraban ya estipulados en otras convenciones. Con el fin de evitar conflicto entre las disposiciones existentes y las de la Convención, se establece de manera explícita que nada de lo dispuesto en la Convención de Nairobi iría en contra de lo estipulado por la Convemar. ${ }^{33}$

\section{CONCLUSIONES}

La remoción de restos de naufragio ha seguido un camino de uniformidad internacional que ha trascendido la regulación estrictamente cultural, para situarse en un problema práctico, comercial y creciente: las embarcaciones mercantes abandonadas en puertos de todo el mundo y el consecuente problema para la seguridad de la navegación que ello implica.

En este contexto, la Convención de Nairobi es un instrumento pragmático, que cuenta con soluciones de índole registral y financiero que ofrecen a los Estados ribereños herramientas para llevar a cabo una tarea integral de limpieza en el ámbito geográfico determinado por la propia Convención.

Por las bondades ya explicadas aquí, la Convención de Nairobi debe transitar un proceso intenso y favorable de ratificaciones y de entrada en vigor. Sin embargo, el éxito de su regulación dependerá de la implementación que realicen tanto los Estados de bandera como los Estados ribereños.

33 En una nota presentada por los Estados Unidos se propusieron dos alternativas para aclarar que no era la intención de la Convención el otorgar a los Estados ribereños mayores derechos con respecto a los restos de naufragio que aquellos que sean reconocidos de conformidad con el derecho internacional consuetudinario. 